\title{
An Exploratory Study of Perceptual and Cognitive Features in Near-Death Experiences: A Proposed Model and Research Recommendations
}

\author{
Jean-Pierre Jourdan, MD \\ Oraison, France \\ John Smythies, MD, FRCP \\ University of California, San Diego
}

\begin{abstract}
This exploratory study was based on the cognitive and perceptual characteristics of 50 cases of near-death experiences (NDEs) collected through the International Association for Near-Death Studies-France. This study resulted in the formulation of a model of perception based on the concept of "global perception" or "global acquisition of information." Further analysis showed that this model is consistent with the concept that these perceptions are not purely hallucinatory but are, in part, modified perceptions of reality. Several clues are then proposed to explain how this type of information could be processed at the cerebral level and beyond. Finally, we offer a clinical research protocol, including a test that could lead to irrefutable proof of veridical perception during NDEs.
\end{abstract}

KEY WORDS: near-death experiences, modeling, global perception, the fifth dimension, consciousness-brain relationship, clinical research protocol, veridical perception

Jean-Pierre Jourdan, MD, is president of, and director of medical research, at the International Association for Near-Death Studies-France. John Smythies, MD, FRCP, prior to his passing in January, 2019, had served as director of the Laboratory for Integrative Neuroscience, Center for Brain and Cognition, University of California at San Diego, La Jolla, CA, and was Charles Byron Ireland Professor of Psychiatric Research Emeritus in the Department of Psychiatry, University of Alabama at Birmingham, Birmingham, AL. The authors wish to thank Robert Mays, Suzanne Mays, and Janice Miner Holden for their extensive editorial contributions to this article. Correspondence regarding this article should be sent to Dr. Jourdan at email: doc-jourdan@wanadoo.fr. 
Following what, for any outside observer, appeared to be a period of unconsciousness, people quite frequently have claimed to recall having very clearly perceived details about the environments surrounding their physical bodies that were later confirmed to be accurate (Holden, 2009). In some cases, they recalled their resuscitation, extrication, or some peri-anesthetic reaction in such detail that the exact moment of the perception could be determined. These apparently nonphysical veridical perceptions (AVPs; p. 186) associated with near-death experiences (NDEs) are one of the major areas of focus in the field of near-death studies, because they challenge the prevailing reductionist paradigm whereby perception can occur only through the mediation of the five senses and the brain.

The first AVP account that sparked the interest of one of us (Jourdan-henceforth "I") was given to me by a nurse. One day, when he was a student nurse, he was in a hospital corridor when he saw an old man heading towards him, laughingly saying, "So, did you find your board in the end ... ?" Seeing the student nurse's surprised expression, the man started to explain: "You don't remember me, but I remember you!"

After a moment's reflection, the student nurse then remembered that this elderly Algerian man had been brought into the Emergency Ward in cardiac arrest some time previously. The old man proceeded to explain:

I saw everything from up there, when you tried to get my heart going again ... Then they asked you to go and get a board, and you panicked: You were looking everywhere for it, but it wasn't where it was supposed to be ... I followed you all the time and you ended up finding it in the kitchen.

Although the patient had been in a state of cardiac arrest and thus was totally unconscious at that moment, what he described was quite correct: The resuscitator had sent the student nurse to look for the board that is used to provide a firm surface when carrying out cardiac massages. A worker had washed it and, instead of putting it back where it should have been, left it to dry in the nurses' dining hall-which explained the student nurse's panicky run through the corridors. The question is: How did the old man, who was unconscious when he arrived in the emergency ward, manage to "see" the scene and remember it in such a vivid way, to such a degree in fact that he could recognize the nurse and describe a particular event that occurred rooms away from where his unconscious body lay? 
A classic NDE usually comprises two primary aspects: (a) perception of the material world, and (b) perception and interaction with transmaterial domains and entities: moving through a tunnel, perceiving a brilliant light, encountering a "being of light" and/or deceased relatives, experiencing a life review, and perceiving a limit or boundary not to be crossed (Holden, 2009). Although in the NDE literature the material aspect is often referred to as an out-of-body experience (OBE), near-death experiencers (NDErs) typically report that during the transmaterial aspect they also were "out-of-body"; hence, the entire NDE is actually an extended OBE-with material and transmaterial aspects. The specific contents of these two aspects of NDEs, although very similar between different accounts, are for the time being mostly beyond the reach of objective study. However, the material aspect, in particular, involves perception of some apparently objective elements and is, therefore, a good candidate for scientific investigation (Holden, 2009).

\section{Previous Studies}

Michael Sabom $(1982,1998)$ reported and studied many cases of AVP by comparing NDE accounts to resuscitation and surgical reports, and two recent cases have been the subject of close investigation (Sartori, Badham, \& Fenwick, 2006; Smit, 2008). Janice Miner Holden (2009) recently provided an extensive discussion of AVPs and the numerous questions they raise. It is important to distinguish NDEs from other experiences of altered consciousness. For example, despite a superficial similarity, the material aspect within NDEs is quite different from well-known and well-explained OBE-like phenomena occurring during sleep paralysis or lucid dreams (Jourdan, 2006).

Regarding the phenomenon of perioperative memory-memories of the operation itself usually due to insufficient anesthesia-whereas prospective clinical studies of cardio-respiratory arrest survivors have consistently yielded a 10-20\% rate of NDEs (Greyson, 2003; Parnia et al., 2001; Sabom, 1983; Sartori, 2004, 2006; Schwaninger, Eisenberg, Schechtman, \& Weiss, 2002; van Lommel, van Wees, Meyers, \& Elfferich, 2001), perioperative memory involves only between $0.2 \%$ and $2 \%$ of patients. In addition to incidence, content also differs. Whereas most NDErs report a predominantly pleasurable experience (Bush, 2009; Zingrone \& Alvarado, 2009), perioperative memories understandably involve predominantly distressing experiences: a sensation of paralysis, feelings of anxiety and panic, a sense of total abandon- 
ment, and, subsequently, post-traumatic symptoms (Bailey \& Jones, 1997; Cobcroft \& Forsdick, 1993).

Despite numerous studies that show the reality and the importance of the problem that NDEs present to a current understanding of consciousness, no theorist so far has proposed an explanation that satisfactorily addresses all aspects of NDEs (Greyson, Kelly, \& Kelly, 2009). In the model we propose herein, we have sought to consider NDEs in the simplest possible terms: as a process of acquiring information. We contend that what initially may seem an unusual, "exotic" effect of conscious perception actually manifests an underlying coherence and follows very strict rules.

\section{The Initial Case}

Our proposed model originated in the late 1990s when a young man told me about his NDE and the way he had "seen" during it, which seemed very strange to me at the time. He said,

It's very difficult to explain, but I was able to see the sofa and my body simultaneously from all directions. I saw my body through the sofa, I could see the top of my head, and at the same time I saw my left and right sides and the sofa from below and from above, and all the room like that. I was everywhere at the same time, you see?

As I had some difficulty understanding this explanation, he dashed off several sketches-front and side-on views as well as views from above and below-repeating, "I saw all that at the same time. ..."

Trying to understand this unusual account, I drew a little man lying on a sofa, viewed from above. Then, to schematize the description "perception from everywhere" that the experiencer was providing, I drew a circle around the scene to represent the projection of a three-dimensional sphere on the two-dimensional paper (see Figure 1). Trying to transpose the phenomenon onto the human world, I mused aloud: "In fact, it's as if you had 'seen' simultaneously from all points of a sphere surrounding the scene." At that moment, considering the drawing, I realized that there was no need to imagine anything as complicated as that. Indeed, a simple glance at the drawing allowed me to see every side of the couch and of the body simultaneously. Moreover, the back of the sofa did not need to be transparent to allow seeing the left side of the body lying on it. 


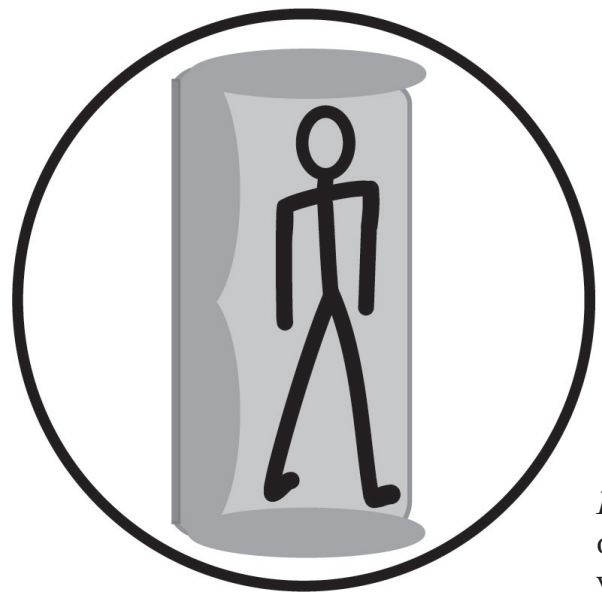

Figure 1. Interpretive sketch of neardeath experiencer's description of visual perception during NDE

\section{Goals and Hypotheses}

If I was able to perceive simultaneously everything in the drawing, it was because I was watching this two-dimensional sketch from a certain distance in a third dimension. This perception "from outside" simply allowed a global perception or a global acquisition of information. This concept of global perception seemed to correspond to the idea that during an NDE, the experiencer is perceiving without the use of the physical bodily senses, and it seemed also to correspond with the "multifaceted perception" that Ring and Cooper (1997) described in their study of physically blind persons' NDEs.

But was it as simple as that? Humans livein a four-dimensional spatiotemporal universe; thus, the scene the experiencer described was fourdimensional. Nevertheless, during this man's NDE, he seemed to have perceived from a perspective external to the usual universe. Of course, for many years physicists and cosmologists have developed several theories considering the existence of additional dimensions and have searched for signs of their existence-but so far unsuccessfully. I decided that this concept could be a good basis of a geometrical model for understanding and analyzing the particular perceptions described in NDEs.

Going back to archival files of the International Association for Near-Death Studies-France (IANDS-France), I found several cases reporting perceptual features similar to the young man's. Preliminary studies (Jourdan, 2000, 2001, 2006) enabled me to distinguish a num- 
ber of constants that showed the relevance of the present study and of the model set out in this paper.

The purposes of this study were (a) to investigate the type of perception that experiencers described; (b) to examine the particular modalities of perception within the material aspect of the NDE; (c) to assess the match of these modalities with a model of global acquiring of information similar to a perception from outside the observed universe, thus from an extra dimension; and (d) to define an experimental protocol to investigate the degree of objectivity of global perception. The working hypothesis was that every particular feature that NDErs report results from the brain reprocessing a global acquiring of information, translating this information into ordinary perceptive concepts.

\section{Method}

The participants in this study were self-identified NDErs who had contacted IANDS-France following a newspaper article, an IANDSFrance publication, or a radio/TV broadcast in which IANDS-France was referenced or participated, and who subsequently were interviewed or completed a written questionnaire addressing global features of NDEs. At the time of the study, the archives contained data from a total of about 100 cases. In a review of the data, 50 interviews or questionnaires in which experiencers made some reference to the phase of the NDE in which they perceived the physical, material world ("material NDEs") were relevant and comprehensive enough to be usable. These 50 individuals comprised the sample for this study.

When possible, meetings had been organized and interviews conducted and recorded by me or another IANDS-France volunteer, then transcribed for analysis. Otherwise, after an initial phone contact and interview, a questionnaire was emailed to the participant, which the participant completed in writing and returned.

First, each participant was asked to freely relate or write down the NDE. Then the participant completed a questionnaire that I and the IANDS-France scientific committee had designed to assess demographics and to inquire in detail about features of the NDE. From 1987 to 1999, this questionnaire (Q1) consisted of 69 open-ended items concerned with only the basic features of NDEs. In 2000, a more specific questionnaire (Q2) was added consisting of two parts. One part was 57 additional open-ended items addressing the state of consciousness experienced, emotions and decisions, particularities and modalities of perception of space and time, information-acquiring ability, and 
Table 1 Demographic and Other Features of IANDS-France Sample of NearDeath Experiencers

\begin{tabular}{l|c|c|c|c|c|c|c}
\hline & $\begin{array}{c}\text { Sample } \\
\text { Size }\end{array}$ & \multicolumn{2}{|c|}{ Age at NDE } & \multicolumn{2}{c|}{$\begin{array}{c}\text { Years from NDE } \\
\text { to Interview }\end{array}$} & \multicolumn{2}{c}{$\begin{array}{c}\text { NDE Scale Scores } \\
\text { (Q2 respondents only) }\end{array}$} \\
\hline & & $M$ & $\mathrm{SD}$ & $M$ & $\mathrm{SD}$ & $M$ & $\mathrm{SD}$ \\
Female & $n=30$ & 24.8 & 9.74 & 21.13 & 10.6 & $18.4(n=13)$ & 4.25 \\
Male & $n=20$ & 27.9 & 9.30 & 16.5 & 10.9 & $18.9(n=10)$ & 6.50 \\
& & & & & & & \\
Combined & $N=50$ & 26.0 & 9.68 & 17.8 & 11.3 & $18.6(n=23)$ & 5.25 \\
\hline
\end{tabular}

memory formation during the NDE. The second part was the 16 -item Near-Death Experience Scale (NDE Scale; Greyson, 1983), an instrument with strong psychometric properties that NDE researchers have used extensively to assess the presence (score 7 or higher out of a possible 32) and depth (higher score indicating deeper) of an NDE. Participant demographic and other information are summarized in Table 1.

All open-ended questions were intended to elicit from NDErs the most comprehensive information about their experiences. Each answer or excerpt in this paper has been translated from the French as faithfully as possible by me.

Accounts were assessed by analyzing the participants' spontaneous statements and the answers to the questionnaires. We categorized the cases according to the following criteria:

- Material NDEs $(N=50)$ : cases involving a component in which, at the very least, participants declared having "seen" their bodies and/or their physical surroundings, whether or not their perceptions were otherwise detailed and/or verified.

- AVPs $(n=28)$ : a subset of the 50 material NDE cases in which participants reported precise perceptions apparently not through their physical senses, corresponding to self-reported verified details in the environment. As almost all testimonies were recorded several years after the NDEs, this criterion was based on our confidence in participants' statements.

We also sought to identify within the accounts any recurring themes that, in essence, "deconstructed" the perceptual process during the material aspect of the NDE. 


\section{Results}

All 23 of the 50 participants who completed the NDE Scale scored 7 or higher. Thus, their self-identification as NDErs was confirmed by objective assessment instrument scores. Although objective assessment was absent for the other 27 self-identified NDErs, a detailed review of their testimonies with regard to NDE Scale items indicated that if they had been able to complete the scale they would have scored well above 7, which lends credibility to the assumption that they were within the verification range.

Concerning spatial perceptions, we identified six perceptual themes that recurred in our participants' NDE accounts. These perceptions were clearly divergent from everyday physical perception:

- Non-sensory perception: participants' reports that their perceptions did not involve their physical sense organs, such as eyes and/or ears.

- Perception at any distance: participants' statements that they perceived some phenomena outside the vicinity of their physical bodies-with some such perceptions a posteriori verified as accurate.

- Omni-directional "vision:" participants' reference to "seeing" in all directions; a $360^{\circ}$ or spherical "vision."

- Simultaneous omni-directionality: participants' declaration that they "saw" an object or a scene from "everywhere at once."

- Perception through solid matter: participants' descriptions of "vision by transparency" through an object that, in physical perception, would have constituted a perceptual barrier.

- Instantaneous (re)location of focus, or "zoom": participants' reports that during their NDEs when they were interested in a detail or other phenomenon, their focus would instantly locate or relocate close to it and/or "zoom in" on it.

The incidence of each of these phenomena among our 50 material NDE sample is summarized in Table 2.

These tables require some comments. Although the spontaneous statements (Q1) were more detailed than mere anecdotes, the proportion of participants reporting details and perceptual particularities increased dramatically when they were required to make an effort to remember $(\mathrm{Q} 1+\mathrm{Q} 2)$. This difference was particularly striking regarding non-sensory perception: Prior to my asking participants about their mode of perception during their NDEs, a minority (16.6\%) spontaneously realized that they actually had not physically seen or heard anything through physical sense organs during their experiences; however, in response to my request that they describe more specifically 
Table 2 Incidence of Various Perceptual Themes from Accounts of Material NDEs

\begin{tabular}{lcccc}
\hline \multicolumn{1}{c}{$\begin{array}{c}\text { Perceptual } \\
\text { features }\end{array}$} & $\begin{array}{c}\text { Q1 (1987-99) } \\
\boldsymbol{n}=\mathbf{3 0}\end{array}$ & $\begin{array}{c}\text { Q1+Q2 (2000-06) } \\
\mathbf{n = 2 0}\end{array}$ & $\begin{array}{c}\text { Total Material } \\
\text { (incl. AVP) } \\
\mathbf{N = 5 0}\end{array}$ & $\begin{array}{c}\text { AVPs only } \\
\boldsymbol{n}=\mathbf{2 8}\end{array}$ \\
\hline AVPs & $14(46.6 \%)$ & $14(70.0 \%)$ & $28(56.0 \%)$ & \\
Non-sensory & $5(16.6 \%)$ & $13(65.0 \%)$ & $18(36.0 \%)$ & $10(35.7 \%)$ \\
At any distance & $13(43.3 \%)$ & $7(35.0 \%)$ & $20(40.0 \%)$ & $16(57.1 \%)$ \\
$\begin{array}{l}\text { Omni-directional } \\
\text { Simultaneous }\end{array}$ & $7(23.3 \%)$ & $12(60.0 \%)$ & $19(38.0 \%)$ & $9(32.2 \%)$ \\
$\begin{array}{l}\text { Instantaneous } \\
\text { relocation }\end{array}$ & $7(23.3 \%)$ & $7(35.0 \%)$ & $14(28.0 \%)$ & $7(25.0 \%)$ \\
$\begin{array}{l}\text { Through solid } \\
\text { matter }\end{array}$ & $10(33.3 \%)$ & $10(50.0 \%)$ & $20(40.0 \%)$ & $11(39.3 \%)$ \\
\hline
\end{tabular}

their mode of perception, a majority (65\%) reported this realization. The same phenomenon was observed in the case of AVPs, whereby the increase was from $46.6 \%$ in Q1 to $70 \%$ in Q2. For us, this finding confirmed our impression resulting from hundreds of interviews that the emotional burden resulting from an NDE drives the experiencer's focus away from the details of the material aspect. The material aspect is actually not the reason why the NDE is an overwhelming experience leading to a change of values and life goals. Therefore, the spontaneous memories of the material aspect of NDEs are not in the foreground of their attentional priorities. Our finding was analogous to results from another altered state of consciousness: dreams. Although people reporting spontaneously on color in their dreams report it only $16-23 \%$ of the time, those asked to specify the color of a particular object in the dream report it $70-83 \%$ of the time (Kahn, Dement, Fisher, \& Barmack, 1962). Whereas an NDE and a dream are distinct experiences, in both cases an experiencer is less likely to report on the process of perception unless a curious researcher directs 
the experiencer to do so-upon which direction the experiencer can rather readily provide details.

The comparison of the percentages of each perceptual feature between the AVPs and the entire OBE sample shows that they are almost identical, which is in favor of the consistency of the phenomenon. The only exception concerns people who have "visited" more or less remote places ("At any distance"), which are more numerous among AVPs, possibly suggesting that these persons have a more focused mind.

\section{Participants' Narratives and an Illustrative Parable Non-Sensory Perception}

Even if at first many participants did not wonder about the way they perceived during their experience, some of them spontaneously realized that they actually had not physically seen or heard anything. Most of them came to this realization later when being asked to describe their mode of perception more precisely.

The following quotes are some examples of answers to the following question: "Try specifying the way in which you perceived what you have described. Did you 'see' or 'hear' as with your eyes and ears, or in a different manner? If different, try to describe how, as accurately as possible."

One perceives and hears all that is happening very clearly but not inside the body. It is not the body that perceives; it is very different. The impressions are more of the visual type, but I can't say how we perceive, it is not the usual senses, sight included ... There isn't any separation between the senses. One is at the same time oneself and what one observes. There is sight and feeling at the same time, a sort of link, an intimate perception of whatever one observes. (A.S.)

The memories I have of those moments are not visual; they are strong inner feelings, as clear as any other ordinary experience, but I cannot talk about images, shapes, etc., as such. (A.T.)

More like an immediate understanding, an awareness; it is the relationship between the observer/observed thing that changes. There isn't that usual inner/outer. (D.D.)

A global perception. (J-M.M)

All my senses were merged, no separation amongst them. (M.M.)

I would say a global perception, making a whole. (D.U.)

It was seeing and knowing at the same time. (D.D.)

I saw and felt, all mixed together! I can't be "technical" and separate what cannot be separated. (C.D.) 
A few examples of "auditory" perception from our respondents corresponded to a model of global perception that cannot be reduced to the usual perception from sensory organs:

None of the usual five senses, but I saw, I felt, I perceived with other senses. Sight, hearing, well, let's say hearing on an immaterial level since it was without words. ... (C.N.)

The sense of hearing, I don't remember it well. I had rather the feeling of hearing others within me. I don't know how to describe it, the "sounds" are soft, harmonious, unreal, welcoming, but they are not sounds. You see everywhere at once and you don't hear the same, if one can call that hearing. (Be.N.)

No sounds. Sometimes, the lips would move but no sound. Simply, the sense of what is said is received. (L.T.)

An Illustrative Parable. To help convey our understanding of our participants' meaning, we provide a parable in which the main character is Tweedee, who possesses only two dimensions (2D). He lives in the diagram in Figure 2 and does not possess any thickness, not even that of the ink with which the Figure is printed. Tweedee is the owner of this two-dimensional house. You, the reader, can see him in his bed inside his bedroom. Tweedee and his domain are reminiscent

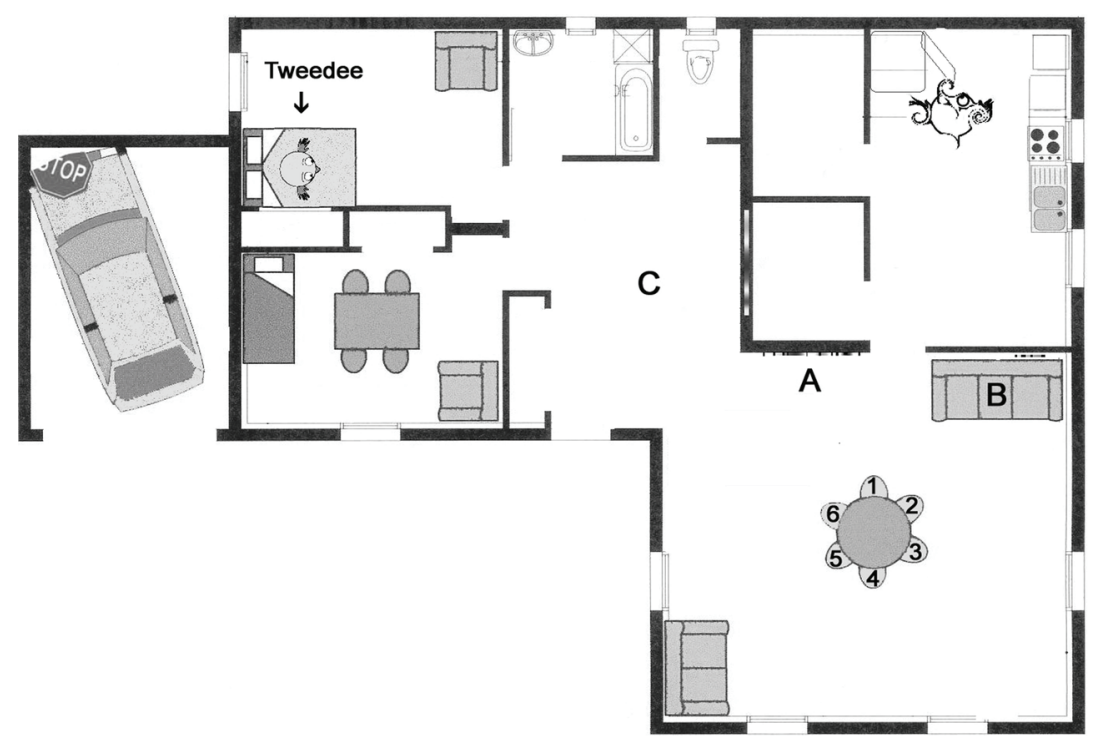

Figure 2. Tweedee's two-dimensional house 
of Edwin A. Abbott's (1884) book about the particularities of a twodimensional world called Flatland. The inhabitants of Flatland can see objects only edge-on, that is, they can see only the edges of the objects in their world. The inhabitants know only two directions: forward or backward, and left or right; they have no experience or conception of above or below.

From point A, located in the living room, Tweedee is able to see the one-dimensional (1D) painting hanging on the living room wall at A. It appears to him as a line made of many different colors. Turning around, he will see the coffee table, and, from this location, he is able to see the stools 2, 1, 6, and 5 edge-on. But he cannot see stools 3 and 4, hidden from him, unless he goes around the table. Tweedee will need to go into the garage to realize that, once again, his stepmother has borrowed his car-and has managed to smash it into a stop sign. Going to the kitchen, he will catch her rummaging through the fridge.

Basically, Tweedee's perceptual process involves nothing out of the ordinary: He cannot see through walls: Another one-dimensional painting in the safe, situated inside the wall to the right of $\mathrm{C}$, is not visible to him. He cannot see what is behind an opaque object any more than humans can in their own environments-for example, his ID (identity) card hidden behind the sofa at B.

Is this "normal?" Yes-for Tweedee. But you, dear reader, can see Tweedee's house in its entirety at a glance; you do not need to move around to see the damaged car or his stepmother. All the stools are visible simultaneously, as well as the paintings, without the need to turn around or see through the walls. Your perceptual ability is the result of your viewing the diagram from a third dimension of height. However, Tweedee is a 2D observer situated within a 2D space of only length and width.

This phenomenon can be summarized as: The information contained in a two-dimensional universe is perceptible in its entirety at a glance from a place located outside this universe: in a third dimension. And to generalize: The information contained in any $\mathrm{N}$-dimensional universe is perceptible in its entirety from a place located outside this universe: in an $N+1$ dimension.

The two totally different viewpoints of Tweedee's house-Tweedee's viewpoint and the reader's viewpoint-are both equally valid, and it is by comparing them that I will now try to establish a model of the seemingly irrational perceptions described as having occurred during NDEs.

In the $2 \mathrm{D}$ picture of his house shown above, contrary to what it may 
seem, Tweedee is unable to lie on his bed, because there is neither above nor below in his universe. The black walls are opaque, and are both visually and physically impenetrable to him, just as concrete is for humans.

In our parable, upon seeing the condition in which his stepmother returned the car, Tweedee went to bed and proceeded to have a heart attack. Furthermore, during this heart attack, he had an NDE.

The hypothesis to test is the following: Tweedee is now experiencing the global perception typical of NDEs. During his NDE, his experience will be congruent with the experience you and I have of his flat universe, namely, observing it from a few inches "outside" the twodimensional plane of the page.

But what is perfectly normal and common for us is not for him. When he returns, how will he manage to interpret and describe the particular features of this perception to his $2 D$ contemporaries? How could he explain his new perceptions "from outside" to $2 \mathrm{D}$ beings who have no experience, and thus no concept, of height at all?

Following are some excerpts in which NDErs from our sample described "seeing" a scene or the environment in a way that is unusual for people in everyday life-but nevertheless quite common during these experiences (text in italics throughout the excerpts in this article indicates emphasis added):

NDEr: I was at ceiling level in the emergency room, above my head. I could see myself lying down on the bed. A (male) doctor was using the resuscitation machines on my left. I could hear ringing noises everywhere. It was quite surreal. A nurse was close to me, adjusting perfusions and other tubes. Another nurse was running back and forth between the doctor and my bed, leaving the room and then coming back, running, all the time. The nurse next to me was talking to me, "Stay with us, this isn't the time to leave." I saw her slapping me.

I was fine. I no longer felt pain. What could be verified was the number of people in the room and what they were doing and saying.

Interviewer: Did the notions of up and down, left and right have any meaning?

NDEr: Yes. During the resuscitation scene I was at ceiling level. It is a notion of the orientation of things, in relation to each other. Not a real geographical, physical, position. It's hard to explain.

Interviewer: Is there a difference (or a contradiction) between what you perceive (things stay in their usual positions with respect to one another) and the fact that the scene is perceived in a global way, meaning that it would be impossible to define the object's position from your standpoint? 
NDEr: No, for me there is no contradiction. People and things are properly oriented in respect to one another in three dimensions. However, one sees the scene globally, by this I mean in its entirety. It's difficult to explain.

For example, [when perceiving the physical world from the physical body] you can't see an object if a person who is standing on the ground is positioned in front of that object. You would need to move in order to see it. In this instance [while perceiving during the NDE], it's different. The person is really in front of the object. The way things are oriented stays the same. However, you can still see the object. You don't need to move. You see the entire scene.

On the ground, you need to move, to change your angle of vision to see everything. There, one is able to see everything without having to move. But people and things are placed normally in respect to one another.

Interviewer: Did you have the impression of having a larger angle of vision, to see in front and behind you simultaneously?

NDEr: Yes. Total, instant vision.

Interviewer: Did you feel like you were seeing an object or scene from multiple locations at once?

NDEr: Yes, absolutely. This is what I meant before when speaking of an orientation but not of a real physical location. Once again, a total, instantaneous vision. (C.P.)

What the NDEr described here corresponds exactly to what Tweedee could say: There is no geographical location. Indeed, in his NDE, Tweedee's point of perception cannot be located anywhere inside what he perceives. At the very most, one can define a point of projection perpendicular to the universe Tweedee observes. From this point, he "sees the scene globally," and it would in fact be difficult for him to explain this perspective to people who had no experiential frame of reference to understand it.

During his NDE, Tweedee's stepmother is actually standing in front of the fridge but can't hide it from Tweedee. Indeed, Tweedee has no need to move in order to "see" anything in his house.

In ordinary consciousness, one needs to change one's angle of vision to see everything. In an NDE, the NDEr can see everything without having to move. The people and things in the environment are still placed with respect to one another in a way that corresponds to the physical world; relative positions remain constant. But for the NDEr no object can be hidden by any obstacle whatsoever.

During Tweedee's NDE, the perception of his flat universe from some distance outside is as natural for you and me as it is strange for Tweedee during (and after!) his NDE. 


\section{Omni-Directional Vision at Any Distance}

The following excerpts are from NDErs unless otherwise indicated.

We see everything from all sides simultaneously! I could see everywhere. I had a $360^{\circ}$ angle of vision. (N.D.)

NDEr: This has nothing to do with our everyday perception, which is limited in its field of vision and acuity, which is dazzled or affected by different things such as light or darkness. The $360^{\circ}$ vision is only focused when we move, as if we were aiming at a target. Otherwise, we see everywhere.

Interviewer: Did you have the impression of having wider angle of vision, like the ability to see in front and behind you simultaneously?

NDEr: Yes, without physically turning around, I could see everywhere. (Be.N.)

I had a global perception of the room, like a sphere. My field of vision was wider than usual. Global vision without the need to turn my head left/right or even to turn around. (F.E.)

This " $360^{\circ}$ " perception, which NDErs describe extremely frequently, can be interpreted as a global perception wherein the subject is interested in what surrounds him-or, rather, what surrounds his point of projection. In addition, the perspective "changes a little" while the vision remains complete, which is exactly what happens when one looks at the diagram from a moving point of view:

... It was then that I noticed I could freely move around. That was interesting, new, so I experimented with a few movements. It seems to me that although my view of the room was always a whole, panoramic, the perspective changed a little according to my movements and my position in that space. (F.I.)

\section{Perception "From Everywhere Simultaneously"}

During his NDE, Tweedee's attention is now drawn to his own body that he "perceives" in his room, from a vantage point situated at a few inches above the plane of the page. He will obviously be surprised to simultaneously "see" both his hands, the back of his head as well as the tip of his nose. It is now a "centripetal" global perception (directed toward a center). He will simply have the impression of "seeing" his body from everywhere at once. 
I could see from above, $360^{\circ}$, and from all sides, all at once.

I see/am/feel this matter with my "sight from above," I see/am/feel this matter from underneath, I see/am/feel this matter which fills the room more and more, I see/am sideways, in profile, underneath, in front, behind, from everywhere, I am the spectator/actor/scene.

I had a $360^{\circ}$ spherical-like vision. I saw everything and had different points of observation: above, sideways, frontwards, underneath, it was really extraordinary to see and be all of it at the same time. When I saw the sofa, the furniture and the room in which I was, I was simultaneously above, sideways, from profile, facing forwards . . . it was very clear. (X.S.)

I visited various places I managed to identify afterward. I remember a window in a village, a building with very white plaster, sandcarved windows. The details piqued my interest. This is quite important, since we can't normally do this, like seeing inside and outside at the same time, an impression of a quasi-holographic vision . . Not a panoramic view, but seeing in front, behind, all details at the same time which differs completely from our everyday sight. It is very abundant. (A.S.)

In everyday life, perceiving from one point means standing at that particular point, and moving closer to an object is the best way to examine it. Therefore, when an experiencer is able to "see" several places simultaneously, a perceptual conflict appears with the feeling of being simultaneously at these different places. For example, Tweedee will be led, like you and me, to simultaneously "see" every room in his house if the distance that separates him and his universe grows. This is exactly how J.M.P "saw"-and was everywhere in-an entire clinic, or A.L. who found herself at home and simultaneously at her grandmother's:

. . because I found myself above, on the bottom, everywhere all at once in the clinic . . . I told you earlier on that I was in the bedroom or more precisely in Mrs. E's bathroom. So, to tell you whether I used the stairs or not, no, I don't think I did; hmm . . . This spatial movement can't be explained since I was actually downstairs and upstairs, and everywhere all at once. (J.M.P.)

The funny thing is that we have a greatly enlarged vision of things. It was as if I was in many places at once. After taking a shower my children went to the village, to my grandmother's who lived across from our house. It was located on the other side of a big valley about 800 meters away. She often watched what was happening at our place with her binoculars. So, at the same time, I also found myself at my grandmother's, who was saying: "Oh, something must have happened 
over at the parents' place because the ambulance is there..." She was watching with her binoculars, the children watched the scene with her through the window, and I was behind them! It is a very strange feeling, everything I saw was very bright, very clear, and my senses were sharpened, a much sharper perception of things. I saw and heard everything, all while being in a coma. (A.L.)

\section{Instantaneous (Re)location of Focus and Zoom}

The same perceptual conflict exists in a "dynamic" manner, translating as some difficulties in discrimination between an instantaneous displacement and a visual zooming sensation.

If Tweedee's attention is attracted to a detail, it will focus on this, just as your gaze can instantly switch from the stepmother to the garage where your eyes will rapidly be caught by the incongruous "STOP" sign. Yet, nothing passed through walls or moved around. The only things that changed are your point of interest and the direction of your gaze.

The impressions resulting from these particular features are of two types. The first is being able to move instantly, depending on what attracts one's attention:

Moving around is done as if time does not exist anymore (or nearly). We "think" about where we wish to be, we make a volitional effort, and we get there instantaneously (or nearly, since there is a sensation of movement, but very fast). (D.U.)

My consciousness, like a beam of light, can move around very fast, nearly instantly. Additionally, this gaze, just like a thought, can move about very quickly from points that are far from one another. (P.C.)

Feeling of relocation, but ultrafast. (M.L.)

Relocation: in one go (F.U.)

The second type of impression is logically associated with the first, namely, being able to "zoom" in on a detail or any other phenomenon of interest. Rather than an instantaneous relocation, zooming involves a sense of movement:

A sort of sliding, moving by zooming. (J-Y.C.)

Interviewer: How did this relocation happen (instantly or not, sensation of moving, sense of speed, more of a zooming sensation without real relocation, etc.)? 
NDEr: This relocation was instantaneous-but the question "More of a zooming sensation without real relocation" bothers me-and it seems more or less that this is how it happened ... I reached an understanding of this phenomenon thanks to a computer game that I've recently played where the hero "Predator" often used this "Zoom" function to move about. Every time I pressed the "Zoom" button I was both disturbed and happy to use this function ... which in fact reminded me of this state. Maybe this is why I felt so light . . (maybe I wasn't moving about after all, maybe it was my highly developed vision which gave me the feeling of moving about ....) (F.E.)

Be.N. used the expression "being hurled" which relates to a physical relocation when associated with the sensation of zooming. Explaining this unusual perception mode can be very complex, and the following narrative is a perfect illustration of this point:

NDEr: I see everywhere at once, except when I target an object towards which I am "hurled" at great speed, as if I was zooming onto it. . . . Nothing dazzles me, there are no limits to my acuity.

Interviewer: Do you feel like you are moving about?

NDEr: Well, I don't know. It is like a rapidly zooming onto the place I am trying to reach. Like a very fast zoom, I cannot recall if it really is a relocation, or simply a zoom, but I was where I was aiming at, so there is a relocation. (Be.N.)

My relocations were subject to my will with instantaneous effect. Instant zooming of my vision, without any relocation on my part. (J.M.)

One must understand that it works like a zoom and a relocation all at once. When one focuses on something it creates a zoom in. It is the relocation and perception occurring simultaneously which allows this to happen. It is hard to separate them, in the sense that there is no notion of time, thus no time spent moving. (A.S.)

\section{Perception Through Solid Matter}

There are, in Tweedee's house, two things he cannot usually see (Figure 2; highlighted in Figure 3): a masterpiece one-dimensional painting in a safe, installed inside the wall separating the hall and kitchen (to the right of $\mathrm{C}$ ), and the ID card lying behind the couch (B), which he has been looking for for several days.

Just as X.S. had the impression of seeing through the couch, Tweedee will also have the impression of seeing the front and back of the sofa, his ID card, the two sides of the wall, and the painting hidden within it, all at once. And yet in our world, as much as in his, when 


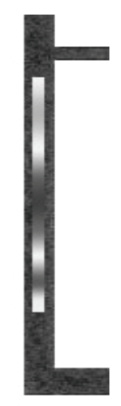

Figure 3. Highlight of

masterpiece painting

and ID card visible

only from above (3rd

dimension)

one can see both the front of and the back of an object as well as things standing behind it, it simply means that this object is transparent.

In fact, our participants' reports indicate that during an NDE, anything that would represent an obstacle for normal vision, such as a curtain, an operating drape, or a wall does not represent an obstacle. Testimonies relating this vision through solid matter were numerous in our sample:

I was surprised that I could see at a $360^{\circ}$ angle: I could see in front and behind me, I could see underneath, I could see far away, I could see up close and also transparently. I remember seeing a stick of lipstick in one of the nurses' pockets. If I wanted to see inside the lamp which illuminated the room, I'd manage to do so, and all of this instantly, as soon as I wanted to. I could see how people were dressed, I could see the sandstone wall, I could also see the stone slabs of the floor. I was able to verify their presence in a photograph later on since I thought it was strange and anachronistic to have such slabs in an operating room. It was surprising and I could see, all at once, a green plaque with white letters saying, "Manufacture de Saint Etienne." The plaque was under the edge of the operating table, covered up by the drape I was lying on. I could see with multiple axes of vision, from many places at once. This is the reason why I saw this plaque under the operating table, from a completely different angle, since I was up there by the ceiling and I still managed to see this plaque located under the table, itself covered by a sheet. When I wanted to check this, the surgeon and I realized the plaque was actually there and read "Manufacture d'armes de Saint Etienne."(J.M.)

I could see everything at once, and if I focused on one thing, I could see this thing through any obstacle and in a very detailed manner from its surface to how its atoms were organized, truly a global and detailed vision. (M.L.) 
This means that I did see the entire accident. I left the car and could see myself from above, thus the car's roof was transparent. (P.F.)

NDEr: I saw myself exit, since I saw my body on the operating table. I was above and could see everything, everywhere, even through the surgeon. One can see everything.

Interviewer: Could you see behind yourself or through objects?

NDEr: Yes, through objects. Since I was passing through the wall. (H.C.)

When I left my body, I could see through all objects. (C.C.)

A very wide vision, through the walls if I wanted to. (K.E.)

I think my normal sight should have been cut off and limited due to the wall stopping at my bed. This wall should have limited my visual capacity - and I feel troubled remembering that . . . (F.E.)

I saw all around me, I saw the inside of my body. (M.H.)

Behind a wall was a woman dying in the resuscitation room. I saw the instruments, the doctors' gestures and their conversation, I could see through the curtains which hung in front of the glass partition. (J-P.L.)

After a while I saw my "hand made out of crystal," and I told myself, "There I can see all the small blood-vessels, but how can it be?" It amused me, nothing more.

I had a global vision, I saw everything at once, I could see everything at once, the impression of seeing backwards and transparently. Sometimes as if I was inside my own eyes. (J-M.M.)

\section{Once at ceiling level I could see through myself. (Be.N.)}

I also saw everything that was happening around me. It was in a tent and thus very dark. I went out of the tent very quickly, but the funny thing was that everything was transparent to me. It was very fast because I was rising rapidly, and I saw through the tent. (P.T.)

I was surrounded by medical personnel, at least six people who seemed to be working on my body. I had the time to see, to see ... well ... I had a very sharp vision and saw through a section of the table. I saw through the operating drape which is around the operation . . . the shoes of ... of one of the resuscitation team probably... One of them had untied shoe laces. (F.U.) 


\section{Discussion}

\section{How Could the Brain Manage Global Information?}

Some recent studies could be relevant concerning the brain's ability to translate global information into understandable percepts and concepts. Cerebral activity of people with congenital deafness were recorded while these individuals were watching a video of a person using sign language (Nishimura et al., 1999). It was expected a priori that the visual cortex would be activated. Instead, activity was recorded in the superior temporal gyrus where the secondary auditory regions enable the interpretation of language. This finding suggests that neural signals of sign language are relayed directly to the auditory centers, which must therefore be perfectly functional despite deafness. This finding has been confirmed by several studies (Finney, Clementz, Hickok, \& Dobkins, 2003; Söderfeldt, Ingvar, Rönnberg, Eriksson, Serrander, \& Stone-Elander, 1997; Söderfeldt, Rönnberg, \& Risberg, 1994).

In a recent study (Collignon, Voss, Lassonde, \& Lepore, 2009), researchers compared auditory evoked potentials in blind participants who were better than sighted individuals at locating the source of a sound. Measurements revealed that during the localization process, the occipital regions of these participants' brains were activatedregions associated with visual processes among sighted persons. Thus, people suffering from blindness seem to perceive their surroundings by processing sound stimuli with the visual regions of their brains.

Another example of sensory crossover is exemplified by Braille reading. PET scan recordings of people with blindness have demonstrated that tasks involving linguistic discrimination-for example, differentiating between real words and words without meaning-prompted an activation of the primary and secondary visual regions, whereas true tactile tasks not requiring linguistic discrimination prompted no activity in these same areas (Held, Freedman, \& Harris, 1996; Sadato, Pascual-Leone, Grafman, Deiber, Ibanez, \& Hallett, 1998).

It is therefore quite plausible for people who experienced an NDE to state that they "saw" or "heard" even though their physical sensory organs were disabled. Even if this mechanism does not explain the experience itself in any way, it seems that after the NDE, several cerebral areas could have extracted, reprocessed, and interpreted relevant information via a sort of global acquisition of information, as unusual as it is inexplicable. 


\section{A Model Involving Extra Dimensions}

Apart from this purely phenomenological approach, the parable we provided leads us to a hypothesized model that the particularities reviewed in this study are simply the reflection of an additional reality. Therefore, the possibility that during an NDE the physical world could actually be perceived from a point located in an additional dimensionand therefore external to normal human space-time-cannot be ruled out. A similar hypothesis has been proposed independently in 2003 by another NDE researcher (Brumblay, 2003). It is important to note that the human universe is not only spatial; it is a four dimensional space-time. Therefore, the additional dimension to which we refer in our model would be a fifth dimension. If the characteristics shown in this study can be considered as spatial four-dimensional perspective effects, the perception of our 4D space-time from an external point of view implies the same distinctive perspective effects when the temporal dimension is introduced. Given the testimonies concerning phenomena such as panoramic life reviews, "visions" of future events, and the feelings of "a second sort of time," of being "out of time," or being in an "eternal present" that are as common within NDEs as the purely spatial perceptions described in this paper, a distinctive five-dimensional spatio-temporal perspective seems to be the case in NDEs. This time issue is addressed in detail with numerous examples in my previous work (Jourdan, 2011, pp. 11-15).

The following is one report that includes global perception, difficulties in distinguishing between relocation and zoom, and above all perception from an external point of view of a four-dimensional object, that is, the whole life of the experiencer, including time:

NDEr: Indeed, at the time I received this new form of intelligence, I was able to observe my life, here . . just in front of my eyes. I find before me ... my life. I look at this $3 D$ thing that is my life and notice that it does not unfold. The time is integrated in it; it is no longer linear. All of one's life is visible, and this "global" intelligence can read it, understand it.

I saw my entire life, in three dimensions, with all the details, people, and situations. But life evolves in a time that does not unfold, being seen from every angle with this universal or global understanding. My life was a shape in front of my eyes, which contained everything and that I consulted.

. . . My whole senses were focused on or condensed in a single understanding concept. The ability to understand and develop ALL, in its wholeness and in its detail. Should I have watched a car, I would 
have known its mileage, fuel quantity, the wear of spark plugs, how many times it had turned left or right, the condition of all its parts, etc. in a split second. It is very difficult to share the encompassing of the three dimensions with the fourth, which merge in a concept that can be easily read when one gets this form of over-intelligence. . . Time is no longer linear. Your own life is in 3D, and the fourth dimension is fully integrated.

Interviewer: Did you feel yourself moving?

NDEr: Yes.

Interviewer: When?

NDEr: To get closer to my life.

Interviewer: How did it happen?

NDEr: A sort of sliding, zoom displacement. To see another part of this

life I just had to change my angle of view. (J-Y.B.)

The concept of additional dimensions has been evoked in the 19th century (Bork 1964) and early 20th century as mathematical and geometric speculations (Bragdon, 1913; Durell, 1938; Manning, 1914; Rucker, 1977, 1984). Trying to unify electromagnetism and gravity, Theodor Kaluza (1921/1983) proposed adding a fifth dimension to space-time. His theory was abandoned but came back with superstrings and string theories initiated by Peter Freund (1982, 1985). But these latter involve 10, 11, or up to 26 extra dimensions, which are curled up at each point of our universe with a finite minuscule size that does not allow the perspective effects reviewed in this study.

On the other hand, brane string theory allows large extra dimensions. (The term "brane" comes from the word "membrane," which refers to a two-dimensional brane.) A p-brane is viewed as a "slice" inside a $(p+1)$ brane. (Here, $p$ is the number of spatial dimensions, a $p$ brane being a $[p+1]$ dimensional space-time.) According to this theory, humans' four-dimensional space-time universe (3 Space +1 Time) is a 3-brane (3S) confined within a 4 -brane (4S), that is namely a fivedimensional space-time $(4 \mathrm{~S}+1 \mathrm{~T})$.

Following some initial proposals (Antoniadis, Arkani-Hamed, Dimopoulos, Dvali, 1998; Arkani-Hamed, Dimopoulos, \& Dvali, 1998; Arkani-Hamed, Dimopoulos, \& Dvali, 2000), Lisa Randall and Raman Sundrum established in 1999 two models of brane cosmology. In the first one (Randall \& Sundrum, 1999a), the size of the extra dimension is finite, about $1 \mathrm{~mm}$, which is obviously insufficient to allow the perspective effects described by the experiencers. But in the second (Randall \& Sundrum, 1999b), the extra-dimension might be infinite, which is compatible with the extra-dimensional modeling that we propose. Another theory, elaborated by the astrophysicist Laurent Not- 
tale (Nottale, 1993, 2011; Nottale \& Timar, 2008), is known as Scale Relativity, in which a fifth topological dimension and a spatialization of time are introduced.

Concerning the status of time within extra-dimensions theories, it seems that this issue has been poorly studied so far: The astrophysicists I contacted told me they were asking the same questions as me (Lisa Randall, 2003, and Bernard Carr, 2004, personal communications).

The link between additional dimensions and consciousness in NDEs was first developed by physical chemist and NDE theorist J. Kenneth Arnette (1992), who proposed that Einstein's general relativity theory allows for connections-"wormholes"-between physical reality and higher dimensions beyond "this universe's definition of time, space, and gravity" (p. 14). In his theory of essence, Arnette (1992, 1995, 1999) proposed that the NDEr's nonmaterial mind or essence separates from the physical body and exists in this higher dimension, free from both time and gravity. The NDEr's experience of a transition from the physical realm - for example, via a tunnel—can be viewed as a passage through a wormhole to another universe, beyond physical space, time, and gravity.

The more general treatment of additional dimensions and consciousness, without specific reference to NDEs, has been studied in particular by neuroscientist John Smythies (1994, 2003, 2009), philosopher Thomas Droulez (2010), mathematician/astronomer Bernard Carr (2008), and physicist James E. Beichler who developed a theory based on a five-dimensional Einstein-Kaluza model of space-time (Beichler, 2008) and also provided very convincing theoretical arguments in favor of the existence of large extra dimensions (Beichler, 2007). Carr (2008) used his astrophysicist expertise to construct a 5D theory of the cosmos that includes consciousness. Smythies (1994, 2003, 2009) presented a series of observational facts from neuroscience and clinical neurology that are difficult to explain with the orthodox 4D theory $(3 \mathrm{~S}, 1 \mathrm{~T})$ of brain-consciousness relations but that fit well with the $5 \mathrm{D}$ theory.

The trail goes back even further. As long ago as 1923, the Cambridge philosopher Charlie Dunbar Broad wrote:

For reasons already stated, it is impossible that sensa [Broad's term for sensations] should literally occupy places in scientific space, though it may not, of course, be impossible to construct a space-like whole of more than three dimensions, in which sensa of all kinds, and scientific objects literally have places. If so, I suppose, that scientific space would be one kind of section of such a quasi-space, and e.g. a visual field would be another kind of section of the same quasi-space. (p. 392) 
Kuhlenbeck (1958) said that "physical events and mental events occur in different space-time systems which have no dimensions in common" (p. 599). Beichler (2007) elaborated Einstein's work with the five-dimensional hypothesis:

Just before passing away, Einstein listed the five-dimensional approach as one of the three possibilities to develop a unified field theory in his last published book (Einstein, 1956). He stipulated that the fivedimensional hypothesis would only be tenable if it could be explained why the fifth dimension cannot be detected. (p. 540)

In answer to Einstein's stipulation as to why humans cannot normally detect the fifth dimension, the explanation that the 5D hypothesis provides is simple. The Observer (Self) is located in this fifth dimension. During normal vision, the visual field of phenomenal objects in consciousness is constructed by a TV-like mechanism in which the brain plays a prominent, but not wholly inclusive, role. So the causal chain reads "(a) physical object-(b) light ray-(c) eye-(d) brain(e) visual field in consciousness." The first four steps take place in physical space (in time). The last step crosses over into phenomenal space (in time). Physical space and phenomenal space are different 3D cross sections (4D with time) of a larger 5D space with time. During an NDE, the first four steps are eliminated, and the Self (Observer) now perceives the physical world directly, that is, as an Observer in the fifth dimension relative to physical space (for details, see Beichler, 2007; Carr, 2008; Droulez, 2010; Smythies, 1994). Thus it is possible that NDEs provide humans with a seeming first glimpse of this extra dimension.

\section{Research and Experimentation}

NDEs are complex experiences, and their role in the expansion of scientific knowledge seems evident. The time for mere statistics is over. Results of clinical studies correspond regarding the existence of NDEs and the frequency with which they occur. Even if they were purely subjective experiences, their importance would not be less. The similarity and coherence amongst multiple accounts worldwide indicate that NDEs are unique, universal human phenomena that deserve close attention.

Statements regarding AVPs during the material aspect of NDEs are often very precise and even commonplace. These perceptions have frequently been verified by medical teams or other credible witnesses present during the experience (Rivas, Dirven \& Smit, 2016). 
This phenomenon raises issues of objectivity and reality. Based on the examples given in this study, we suggest that the cognitive and perceptive features of NDEs show an undeniable consistency. This consistency does not appear immediately. However, analysis via the concepts of "global perception" and "global acquisition of information," as proposed in this paper, confirms the strong internal coherence of this phenomenon, which is worthy of further exploration.

Recent research confirms, if it were needed, the reality and clinical significance of NDEs in all circumstances and the necessity of further exploration. One study by the Coma Science Group from the University of Liège, Belgium, on which I collaborated (Charland-Verville, Jourdan, Thonnard, Ledoux, Donneau, Quertemont, \& Laureys, 2014) showed that NDEs are essentially alike, regardless of the etiology of the experience; indeed, I had many examples in Jourdan (2006, chapter 2). According to the NDE Scale, the intensity and content of NDEs did not differ between the "NDE-like" group, whose experiences occurred in non-life-threatening circumstances, and the "real NDE" group, whose experiences occurred during coma. Nor was there any difference within the "real NDE" coma group based on the cause of coma: anoxic, traumatic, or other cause. This striking similarity, regardless of the physiological state of the brain, could be an important clue regarding the mind-brain problem, as it clearly brings into question the responsibility of the brain in these experiences.

Another striking feature of NDEs is the quality of the memory of the NDE, which is most frequently described as vivid and never fading. I provided many examples and a first analysis in an earlier work (Jourdan, 2006, chapter 9). More recently, another study by the Coma Science Group (Thonnard, Charland-Verville, Brédart, Dehon, Ledoux, Laureys, \& Vanhaudenhuyse, 2013) compared the memories of NDEs with memories of others who were in coma without an NDE and with a paired control group of healthy individuals. Five types of memories were assessed using the Memory Characteristics Questionnaire (MCQ; Johnson, Foley, Suengas, \& Raye, 1988). The target memories were (a) the NDEr's memory of the NDE, (b) the coma patient's memory of the coma, and, for (c) coma patients with no memory of the coma and (d) controls, one's first childhood memory. The target memories were compared to the subjects' real event memories and imagined event memories. The results led to the conclusion that, far from being memories of imaginary events, memories of NDEs have even more characteristics than real event memories, including visual details, memory clarity, self-referential information-being involved in the event, and emotional content. Thus, memories of veridical per- 
ceptions in NDEs cannot be dismissed as false memories of hallucinatory or re-created events any more than memories of the rest of the experience can be.

\section{Objective Perceptions: In Search of an Irrefutable Proof}

The apparently inexplicable nature of the acquisition of information during NDEs raises a number of issues that a systematic scientific approach cannot avoid by arguing its apparent impossibility. During the past few years, several investigators (Greyson, Holden, \& Mounsey, 2006; Holden \& Joesten, 1990; Lawrence, 1996; Parnia et al., 2001, 2014; Sartori, 2004, 2006) have attempted to test the reality of AVPs by setting various targets in places where NDEs were most likely to occur. However, no positive results were observed; researchers have not yet captured AVP under controlled circumstances. Considering its implications, such research needs to be unassailable, and even the slightest piece of evidence should be irrefutable beyond any reasonable doubt.

However, except for Greyson et al. (2006), all of the above-reported studies had one thing in common: In spite of many precautions, it was always possible in one way or another for someone to become acquainted with the targets, such as the nurse who declared regarding Parnia et al.'s AWARE study (2014), "It might be open to contamination by staff like me who wouldn't be able to resist taking a peek at the images."

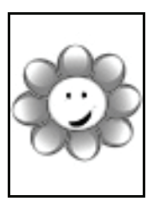

Figure 4. Flower

Therefore, despite its interest on many points and the resources expended by the Parnia et al. (2014) study, any positive result concerning the perception of a target would amount only to anecdotal evidence. Given the number of reported AVPs, it is essential to have confirmation of the acquisition of such evidence under circumstances that do not allow this leak. This stipulation means designing an extremely rigorous protocol to test the objectivity of these perceptions in unequivocal terms, even if its harshness reduces the probability of a positive result. 
The concept of global acquisition of information-as opposed to physical vision-developed in this paper enables the creation of a very simple-and inexpensive!-experiment. Recall from the above section "Perception Through Solid Matter" the examples of the lipstick in the nurse's pocket, the plaque under the operating table, and the untied shoe laces. These details all have several points in common: Although nothing suggests their presence, they are original enough to attract attention while remaining credible, they are easy to memorize, but above all they are hidden from anybody around-except for the NDEr. Therefore, the experiment entails that a "target"-or, to be more precise, the information it contains - be hidden in something completely opaque. The target could be part of what is perceived during an NDE, like the little flower in a 2D envelope-therefore hidden to a $2 \mathrm{D}$ observer - that probably caught your attention when you landed on the previous page, as an unusual contrasting element in the midst of the text (see Figure 4).

Indeed, the target can be placed anywhere in the patient's environment provided it is unusual and interesting enough to catch the NDEr's attention. For this criterion to be met, the target will need to offer some sort of "emotional" contrast and importance with respect to the "high tech" environment of an emergency ward. The most common previous target in the latest studies was a computer screen placed on a shelf or on a support hanging from the ceiling. However, being merely one unremarkable screen among the other screens of medical devices in the operating room, it would have little chance of being a good target.

- Its position, and above all its presence, must be sufficiently plausible so that the witness dares mentioning it in detail without fear of not being taken seriously or seeming insane.

- It will need to be completely unknowable via "normal" means.

Whatever the mechanism involved, the hypothesis claiming that perception during an NDE results from a global acquisition of information and not from vision in the usual sense of the word-which would imply physical interaction-allows the assumption that lighting is not necessary for this perception.

In this experimental design, one of the experimenters will simply need to place target-salient objects or pictures, known only to him, in completely opaque envelopes, numbered in a blind and random manner. Although it does not seem essential, the container could be marked: Look inside without opening! These targets would be planted 
in places where patients in cardio-circulatory arrest or in a coma are likely to be located, such as trauma rooms, ICUs, emergency and reanimation units, and vascular and neurological operating theaters. When an NDE subsequently occurs in that place, after the interrogation of the subject, an examination can be made to see if any of the target objects were accurately identified and, therefore, had seemingly been 'observed' during the NDE.

\section{Conclusion}

The analysis of AVPs in terms of information should enable researchers to conduct research in a way that is purely scientific and free from all a priori assumptions. There may one day be a convincing rational explanation for this phenomenon, or given the current knowledge base it may remain inexplicable for some time. In any event, it now seems clear that the cases possess an undeniable consistency. This fact, thanks to a simple shift in the point of view, allows one to comprehend and to go beyond the apparent irrationality of the accounts. Whether this coherence reflects a particular cerebral functioning, a new 5D phenomenon involving an extra dimension, or a combination of both, it casts doubt on purely hallucinatory interpretations of these experiences and could provide a new avenue for research on the mind-brain relationship. Be that as it may, the "hidden" coherence revealed by this study constitutes an argument in favor of scientific research into NDEs, especially in cognitive sciences, cognitive neuroscience, and all those disciplines in which researchers seek to explore the nature of consciousness, a consciousness that, in the present case, exhibits behavior that is as unusual as it is consistent.

\section{References}

Abbott, E. A. (1884). Flatland: A romance of many dimensions. Retrieved from https://github.com/Ivesvdf/flatland/blob/master/oneside_a4.pdf.

Antoniadis, I., Arkani-Hamed, N., Dimopoulos, S., Dvali, G. (1998). New dimensions at millimeter to a Fermi and superstrings at a TeV, Physics Letters B, 436(3-4), 257-263. doi:10.1016/S0370-2693(98)00860-0

Arkani-Hamed, N., Dimopoulos, S., \& Dvali, G. (1998). The hierarchy problem and new dimensions at a millimeter. Physics Letters B, 429(3-4), 263-272. doi:10.1016/S0370-2693(98)00466-3

Arkani-Hamed, N., Dimopoulos, S., \& Dvali, G. (August 2000). The universe's unseen dimensions. Scientific American, 283(2), 62-69. doi:10.1038/scientific american0800-62 
Arnette, J. K. (1992). On the mind/body problem: The theory of essence. Journal of Near-Death Studies, 11(1), 5-18. doi:10.17514/JNDS-1992-11-1-p5-18.

Arnette, J. K. (1995). The theory of essence. II. An electromagnetic-quantum mechanical model of interactionism. Journal of Near-Death Studies, 14(2), 77-99. doi:10.17514/JNDS-1995-14-2-p77-99.

Arnette, J. K. (1999). The theory of essence. III: Neuroanatomical and neurophysiological aspects of interactionism. Journal of Near-Death Studies, 18(2), 73-101. doi:10.17514/JNDS-1999-18-2-p73-101.

Bailey,A.R.,\&Jones, J.G.(1997).Patients'memoriesofeventsduringgeneralanaesthesia.Anaesthesia, 52(5), 460-476. doi:10.1111/j.1365-2044.1997.133-az0134.x

Beichler, J. E. (2007). Three logical proofs: The five-dimensional reality of spacetime. Journal of Scientific Exploration, 21(3), 523-542.

Beichler, J. E. (2008). To die for: The physical reality of conscious survival. Bloomington, IN: Trafford.

Bork, A. M. (1964). The fourth dimension in nineteenth-century physics. Isis, 55(3), 326-338. doi:10.1086/349865

Bragdon, C. F. (1913/2005). A primer of higher space (The fourth dimension). New York, NY: Cosimo Classics.

Broad, C. D. (1923). Scientific thought. London, England, UK: Routledge \& Kegan Paul.

Brumblay, R. J. (2003). Hyperdimensional perspectives in out-of-body and neardeath experiences. Journal of Near-Death Studies, 21(4), 201-221. doi:10. 17514/JNDS-2003-21-4-p201-221.

Bush, N. E. (2009). Distressing Western near-death experiences: Finding a way through the abyss. In J. M. Holden, B. Greyson, \& D. James (Eds.), The handbook of near-death experiences: Thirty years of investigation (pp. 63-86). Santa Barbara, CA: Praeger/ABC-CLIO.

Carr, B. (2008). Worlds apart? Proceedings of the Society for Psychical Research, $59,1-96$.

Charland-Verville, V., Jourdan, J.-P., Thonnard, M., Ledoux, D., Donneau, A.-F., Quertemont, E., \& Laureys, S. (2014). Near-death experiences in non-lifethreatening events and coma of different etiologies. Frontiers in Hhuman Neuroscience, 8, 203. doi:10.3389/fnhum.2014.00203

Cobcroft, M. D., \& Forsdick, C. (1993). Awareness under anaesthesia: The patients' point of view. Anaesthesia and Intensive Care, 21(6), 837-843.

Collignon, O., Voss, P., Lassonde, M., \& Lepore, F. (2009). Cross-modal plasticity for the spatial processing of sounds in visually deprived subjects. Experimental Brain Research, 192(3), 343-358. doi:10.1007/s00221-008-1553-z

Droulez, T. (2010). Conscience, espace, réalité. Implications d'une critique du réalisme perceptuel direct [Consciousness, space, reality: Implications of a critique of direct perceptual realism]. Cahiers Philosophiques de Strasbourg, 28. $145-174$.

Durell, F. (1938). Mathematical adventures. Boston, MA: Bruce Humphries.

Einstein, A. (1956). The meaning of relativity (5th ed.). Princeton, NJ: Princeton University Press.

Finney, E. M., Clementz, B. A., Hickok, G., \& Dobkins, K. R. (2003). Visual stimuli activate auditory cortex in deaf subjects: Evidence from MEG. Neuroreport, 14(11), 1425-1427. doi:10.1097/00001756-200308060-00004 
Freund, P. G. (1982). Kaluza-Klein cosmologies. Nuclear Physics B, 209(1), 146156. doi:10.1016/0550-3213(82)90106-7

Freund, P. G. (1985). Superstrings from 26 dimensions? Physics Letters B, 151(5-6), 387-390. doi:10.1016/0370-2693(85)91660-0

Greyson, B. (2003). Incidence and correlates of near-death experiences in a cardiac care unit. General hospital psychiatry, 25(4), 269-276. doi:10.1016 /S0163-8343(03)00042-2

Greyson, B., Holden, J. M., \& Mounsey, P. (2006). Failure to elicit near-death experiences in induced cardiac arrest. Journal of Near-Death Studies, 25(2), 85-98. doi:10.17514/JNDS-2006-25-2-p85-98.

Greyson, B., Kelly, E. W., \& Kelly, E. F. (2009). Explanatory models for neardeath experiences. In J. M. Holden, B. Greyson, \& D. James (Eds.), The handbook of near-death experiences: Thirty years of investigation (pp. 213-234). Santa Barbara, CA: Praeger/ABC-CLIO.

Held, R., Freedman, S. J., \& Harris, C. S. (1996). Activation of the primary visual cortex by Braille reading in blind subjects. Nature, 380, 526-528. doi:10.1038/380526a0

Holden, J. M. (2009). Veridical perception in near-death experiences: A comprehensive, critical review of the professional literature. In J. M. Holden, B. Greyson, \& D. James (Eds.), The handbook of near-death experiences: Thirty years of investigation (pp. 185-212). Santa Barbara, CA: Praeger/ABC-CLIO.

Holden, J. M., Greyson B., \& James D. (Eds.). (2009). The handbook of neardeath experiences: Thirty years of investigation. Santa Barbara, CA: Praeger/ ABC-CLIO.

Holden, J. M., \& Joesten, L. (1990). Near-death veridicality research in the hospital setting. Journal of Near-Death Studies, 9(1), 45-54. doi:10.17514 /JNDS-1990-9-1-p45-54.

Johnson, M. K., Foley, M. A., Suengas, A. G., \& Raye, C. L. (1988). Phenomenal characteristics of memories for perceived and imagined autobiographical events. Journal of Experimental Psychology: General, 117(4), 371-376. doi:10.1037/0096-3445.117.4.371

Jourdan, J.-P. (2000). Just an extra dimension . . . Les Cahiers de IANDS-France, special scientific issue No. 1. Retrieved from http://www.iands-france.org/SRC /PDF/justextra.pdf

Jourdan, J.-P. (2001). Les dimensions de la conscience [The dimensions of consciousness]. Les Cahiers de IANDS-France, special scientific issue No. 2. Retrieved from http://www.iands-france.org/res_dimcons.html

Jourdan, J.-P. (2006). Deadline-Dernière limite: EMI, une énigme pour la science: plaidoyer pour une étude scientifique des expériences dites de mort imminente [Deadline-Final limit: NDEs, a mystery for science: Plea for a scientific study of near-death experiences]. Paris, France: Les 3 Orangers.

Jourdan, J.-P. (2011). Near death experiences and the 5th dimensional spatiotemporal perspective. Journal of Cosmology, 14, 4743-4762. Also in (2011) R. Penrose \& S. Hameroff (Eds.), Consciousness and the universe: Quantum physics, evolution, brain \& mind (pp. 622-648). Cambridge, MA: Cosmology Science. Retrieved from http://journalofcosmology.com/Consciousness152.html

Kahn, E., Dement, W., Fisher, C., \& Barmack, J. E. (1962). Incidence of color in immediately recalled dreams. Science, 32, 1054-1055. 
Kaluza, T. (1983). On the problem of unity in physics. In V. de Sabbata \& E. Schmutzer (1983). Unified field theories of more than 4 dimensions including exact solutions. Proceedings of the International School of Cosmology and Gravitation, held at Erice, Italy, 20 May-1 June 1982. (original work published 1921)

Kuhlenbeck, H. (1958). The meaning of "postulational psycho-physical parallelism.” Brain, 81(4), 588-603. doi:10.1093/brain/81.4.588

Lawrence, M. (1996). Prospective near-death experience studies with AIDS and cardiac patients. Paper presented at the annual North American Conference of the International Association for Near-Death Studies, Oakland, CA.

Lawrence, M. (1997). In a world of their own. Westport, CT: Praeger.

Manning, H. P. (1914/1956). Geometry of four dimensions. New York, NY: Dover.

Nishimura, H., Hashikawa, K., Doi, K., Iwaki, T., Watanabe, Y., Kusuoka, H., . . . Kubo, T. (1999). Sign language 'heard' in the auditory cortex. Nature, 397(6715), 116. doi:10.1038/16376

Nottale, L. (1993). Fractal space-time and microphysics: Towards a theory of scale relativity. Singapore: World Scientific. doi:10.1142/1579

Nottale, L. (2011). Scale relativity and fractal space-time: A new approach to unifying relativity and quantum mechanics. London, England, UK: Imperial College Press.

Nottale, L., \& Timar, P. (2008). Relativity of scales: Application to an endoperspective of temporal structures. In S. Vrobel, O. E. Rossler, \& T. MarksTarlow (Eds.), Simultaneity: Temporal structures and observer perspectives (pp. 229-242). Singapore: World Scientific.

Parnia, S., Spearpoint, K., de Vos, G., Fenwick, P., Goldberg, D., Yang, J., . . . \& Schoenfeld, E. R. (2014). AWARE-AWAreness during REsuscitationA prospective study. Resuscitation, 85(12), 1799-1805. doi:10.1016/j.resuscita tion.2014.09.004

Parnia, S., Waller, D. G., Yeates, R., \& Fenwick, P. (2001). A qualitative and quantitative study of the incidence, features and aetiology of near death experiences in cardiac arrest survivors. Resuscitation, 48(2), 149-156. doi:10.1016 /S0300-9572(00)00328-2

Randall, L., \& Sundrum, R. (1999a). Large mass hierarchy from a small extra dimension. Physical Review Letters, 83(17), 3370-3373. doi:10.1103/Phys RevLett.83.3370

Randall, L., \& Sundrum, R. (1999b). An alternative to compactification. Physical Review Letters, 83(23), 4690-4693. doi:10.1103/PhysRevLett.83.4690

Ring, K., \& Cooper, S. (1997). Near-death and out-of-body experiences in the blind: A study of apparent eyeless vision. Journal of Near-Death Studies, 16(2), 101-147. doi:10.17514/JNDS-1997-16-2-p101-147.

Rivas, T., Dirven, A., \& Smit, R. H. (2016). The self does not die: Verified paranormal phenomena from near-death experiences. Durham, NC: International Association for Near-Death Studies.

Rucker, R. (1977). Geometry, relativity and the fourth dimension. Mineola, NY: Dover.

Rucker, R. (1984). The fourth dimension. Boston, MA: Houghton Mifflin.

Sabom, M. B. (1982). Recollections of death: A medical investigation. New York, NY: Simon \& Schuster. 
Sabom, M. B. (1998). Light and death: One doctor's fascinating account of neardeath experiences. Grand Rapids, MI: Zondervan.

Sadato, N., Pascual-Leone, A., Grafman, J., Deiber, M. P., Ibanez, V., \& Hallett, M. (1998). Neural networks for Braille reading by the blind. Brain: A journal of neurology, 121(7), 1213-1229. doi:10.1093/brain/121.7.1213

Sartori, P. (2004). A prospective study of NDEs in an intensive therapy unit. Christian Parapsychologist, 16(2), 34-40.

Sartori, P. (2006). The incidence and phenomenology of near-death experiences. Network Review (Scientific and Medical Network), 90, 23-25.

Sartori, P., Badham, P., \& Fenwick, P. (2006). A prospectively studied neardeath experience with corroborated out-of-body perceptions and unexplained healing. Journal of Near-Death Studies, 25(2), 69-84. doi:10.17514 /JNDS-2006-25-2-p69-84.

Schwaninger, J., Eisenberg, P. R., Schechtman, K. B., \& Weiss, A. N. (2002). A prospective analysis of near-death experiences in cardiac arrest patients. Journal of Near-Death Studies, 20(4), 215-223. doi:10.17514/JNDS-2002-20-4 -p215-223.

Smit, R. H. (2008). Corroboration of the dentures anecdote involving veridical perception in a near-death experience. Journal of Near-Death Studies, 27(1), 47-61. doi:10.17514/JNDS-2008-27-1-p47-61.

Smythies, J. R. (1994). The walls of Plato's cave: The science and philosophy of (brain, consciousness and perception). Aldershot, UK: Avebury.

Smythies, J. (2003). Space, time and consciousness. Journal of Consciousness Studies, 10(3), 47-56.

Smythies, J. (2009). Brain and consciousness: The ghost in the machines. Journal of Scientific Exploration, 23(1), 37-50.

Söderfeldt, B., Rönnberg, J., \& Risberg, J. (1994). Regional cerebral blood flow in sign language users. Brain and Language, 46(1), 59-68. doi:10.1006/brln .1994 .1004

Söderfeldt, B., Ingvar, M., Rönnberg, J., Eriksson, L., Serrander, M., \& StoneElander, S. (1997). Signed and spoken language perception studied by positron emission tomography. Neurology, 49(1), 82-87. doi:10.1212/WNL.49.1.82

Thonnard, M., Charland-Verville, V., Brédart, S., Dehon, H., Ledoux, D., Laureys, S., \& Vanhaudenhuyse, A. (2013). Characteristics of near-death experiences memories as compared to real and imagined events memories. PloS one, 8(3), e57620. doi:10.1371/journal.pone.0057620

van Lommel, P., van Wees, R., Meyers, V., \& Elfferich, I. (2001). Near-death experience in survivors of cardiac arrest: a prospective study in the Netherlands. The Lancet, 358(9298), 2039-2045. doi:10.1016/S0140-6736(01)07100-8

Zingrone, N. L., \& Alvarado, C. S. (2009). Pleasurable Western adult near-death experiences: Features, circumstances, and incidence. In J. M. Holden, B. Greyson, \& D. James (Eds.), The handbook of near-death experiences: Thirty years of investigation (pp. 17-40). Santa Barbara, CA: Praeger/ABC-CLIO. 